\title{
CONSERVATIVE MANAGEMENT OF PERIAPICAL LESIONS OF ENDODONTIC ORIGIN - A REVIEW OF THE DIFFERENT TECHNIQUES
}

\author{
Tsvetelina Borisova-Papancheva, Slavena Svetlozarova
}

\author{
Department of Conservative Dentistry and Oral Pathology, Faculty of Dental Medicine, \\ Medical University of Varna
}

\begin{abstract}
INTRODUCTION: Periapical lesions of endodontic origin are common pathological conditions affecting the periradicular tissues. Mainly responsible for the initiation and progression of apical periodontitis is the microbial infection of pulpal tissues. There are different conservative techniques that can be applied in order to establish a healing process of periapical lesions of endodontic origin.

MATERIALS AND METHODS: We have conducted a research that covers related articles and publications, in order to review the different conservative management treatment techniques for lesions affecting the periradicular tissues.

RESULTS: Different non-surgical management techniques have been described, namely: conservative root canal therapy, decompression technique, a method using calcium hydroxide, aspiration-irrigation technique, lesion sterilization and repair therapy, active non-surgical decompression technique, and the apexum procedure.

CONCLUSION: All of the described management techniques present with advantages, disadvantages and specific indications that should be taken into consideration when managing the treatment plan of every specific clinical case.
\end{abstract}

Keywords: conservative treatment, non-surgical management, periapical lesion, periradicular pathology

Address for correspondence:

Tsvetelina Borisova-Papancheva

Faculty of Dental Medicine

Medical University of Varna

84 Tzar Osvoboditel Blvd

9000 Varna

e-mail:dr_borisova@abv.bg

Received: September 16, 2018

Accepted: December 23, 2018

\section{INTRODUCTION}

One of the most common pathological conditions affecting the periradicular tissues are periapical lesions (1). Periapical lesions develop due to untreated pulp diseases. They often occur without any episode of acute pain and are mainly discovered on routine radiographic examination (2). The microbial invasion and infection of the root canal system of 
the tooth play an important role in the initiation and progression of periapical lesions (3). Therefore the complete elimination of microorganisms and their byproducts from the root canal system as well as the prevention of reinfection play a key role in the management of periapical lesions of endodontic origin.

Periapical pathology can be accessed surgically, non-surgically or using a combined approach. All inflammatory periapical lesions of endodontic origin should always first be considered for conservative treatment because it is less invasive and when done properly leads to elimination of the microorganisms and can initiate a healing process (4). Large periapical lesions and apical true cysts, because of their inflammatory origin, should be considered initially for a non-surgical approach (5). In cases with persistent clinical symptoms and present periapical infection after orthograde endodontic management protocols, a surgical or combined treatment option should be taken into consideration. Surgical approach is also indicated in cases of lack of patency in a root canal that should be retreated, due to large intracanal posts, fractured instruments, calcifications or ledges in the root canal (5).

Studies have reported a success rate of up to $85 \%$ of complete and partial apical healing of lesions following non-surgical endodontic therapy (68). Numerous clinical cases, showing a healing of large periapical lesions after conservative endodontic treatment, have been described (9-11). While deciding on the management approach numerous factors must be considered such as: diagnosis of the lesion, proximity of the lesion to adjacent vital teeth, proximity to anatomical structures, patient cooperation, present obstructions in the root canal system and cases refractory to non-surgical management methods (2). It is suggested that inflammatory apical true cysts and the presence of cholesterol crystals are possible causes, preventing healing of periapical lesions (12). Another factor, influencing the treatment decision is the time, involved for treatment (2). Enhanced healing kinetics are observed after performing apical surgery of teeth with periapical lesions (13).

On the other hand, the surgical approach has a lot of disadvantages and is often bypassed especially in the posterior region due to adjacent anatomical structures, limited access and lack of operator experi- ence (14-16). Appropriate anatomical knowledge and attention to preoperative radiography are proved to play a crucial role in the treatment decision (9). Conebeam computed tomography helps to predict the results and avoid complications regardless of the chosen treatment option (14,17-19).

\section{MATERIALS AND METHODS}

A review of literature was performed in order to systemize the non-surgical management techniques of periapical lesions according to their advantages and disadvantages. Our search proved that various methods can be used in the conservative management of periapical lesions. Monitoring of the healing process is essential through periodic follow-up examinations.

\section{RESULTS}

Our review of literature showed that different techniques can be used in the non-surgical management of periapical pathology of endodontic origin, and namely: conservative root canal therapy, decompression technique, method using calcium hydroxide, aspiration-irrigation technique, lesion sterilization and repair therapy, active non-surgical decompression technique and the apexum procedure $(1,2)$.

Periapical lesions can be classified as granulomas, cysts or periapical inflammations of diffuse origin. Granulomas are composed usually of a solid soft tissue, while cysts are semisolid tissue, surrounded by epithelium (20). Granulomas occurrence ranges between $9.3 \%$ and $87.1 \%$, where the abscess formation rate is between $28.7 \%$ and $70.07 \%$ (21).

All inflammatory periapical lesions should be initially treated with conservative non-surgical procedures (4). In the early 1972 Toller (22) proposed that the growth of the cyst may be connected to the increased hydrostatic pressure of the fluid, which causes additional osteoclastic activity. The decompression and the aspiration-irrigation technique lead to a decrease in the hydrostatic pressure and result in shrinkage of the lesion.

\section{Decompression Technique}

This is a technique that involves placement of a drain into the lesion, regular irrigation, periodic length adjustment if necessary and maintenance of the drain for different period of time (23). Vari- 
ous techniques have been used in order to establish drainage. The drain could either be "I"-shaped piece of rubber dam, hollow tube, polyvinyl polyethylene tube, suction catheter and etc. $(2,24)$. Daily irrigation of the lesion can be performed through the lumen of the drain using $0.12 \%$ chlorhexidine (24). There is no standard protocol for the length of the time, necessary to leave the drain in place. It differs according to the kind, size or location of the lesion (24).

The main advantages of this method are that it is a relatively simple procedure, which minimizes the risk of damaging adjacent vital structures (23). Some of the noted disadvantages include: possible inflammation of the alveolar mucosa, persistence of the surgical defect, development of an acute or chronic infection, possible displacement of the drainage tube (25). This technique is contraindicated in cases of large granulomas or solid lesions, because of the absence of a fluid filled cavity to decompress (23).

\section{Active Non-Surgical Decompression Technique}

This method uses the Endo-eze vacuum system (Ultradent) in order to create a negative pressure, which leads to the decompression of large periapical lesions. A micro 22-gauge needle is inserted into the root canal, activated for 20 minutes, which results in creating a negative pressure and aspiration of the exudates. When the drainage stops, the endodontic access cavity gets closed with temporary cement. Unlike the decompression technique this one is minimally invasive because the entire procedure is performed through the root canal and is therefore easily tolerated by the patient (25).

\section{Aspiration and Irrigation Technique}

The traditional aspiration and irrigation technique involves the creation of buccal and palatal wounds (2). This method involves aspirating the fluid using a wide gauge needle, attached to a syringe. The needle penetrates the lesion through the buccal mucosa, creating a buccal wound, and exits through the palatal mucosa, creating a palatal wound which later acts as a pathway for the escape of the irrigant. A disadvantage of the method is the creation of both wounds, which can result in inflammation of the alveolar mucosa and major discomfort (26).

Aspiration through the root canal minimizes the discomfort of the patient rapidly. It is a simplified technique that aids in decreasing the hydrostat- ic pressure of the bone cavity. Fernandes et al. (27) describe a clinical case, estimating a repair rate of 4 $\mathrm{mm}^{2} 1$ month after performing an aspiration and irrigation technique through the root canal. Because of the fast repair rate the authors decided not to combine the technique with the placement of intracanal medicament. If the repair rate is slow, the technique can be combined with calcium hydroxide therapy is order to fasten the osseous regeneration (6).

As in the traditional aspiration and irrigation technique, case selection is crucial. If it is impossible to remove fluid from the bone cavity, this would indicate the presence of granulation or some other type of soft tissue mass. Clinical cases like these are not indicated for the aspiration and irrigation technique. Severely curved canals as well as very narrow root canals might also limit the use of the technique because the root canal system anatomy in these cases prevents the aspirating needle from reaching the apical foramen (27).

\section{Method Using Calcium Hydroxide}

Calcium hydroxide is a widely used material in the field of endodontics because of its antibacterial effects. It is thought to create favorable conditions for periapical repair and to stimulate hard tissue formation (2). A success rate of $73.8 \%$ has been reported for endodontic treatments with calcium hydroxide of teeth with periapical lesions (6). All biological actions of calcium hydroxide progress by the ionic dissociation in calcium ion and hydroxyl ion. Hydroxyl ions are highly oxidant-free radicals that show extreme reactivity, resulting in the damage of the bacterial cytoplasmic membrane, protein denaturation and damage of the bacterial DNA (28). Different forms of calcium hydroxide and calcium hydroxide-iodoform pastes are available for root canal treatment (29).

Some studies have reported that the long-term exposure of root dentin to calcium hydroxide leads to a decrease in the fracture resistance of the teeth (30).

In 2016, Neskovic et al. (31) reported $67.6 \%$ success rate of orthograde retreatment in cases with chronic periapical inflammation. The conservative retreatment was completed in two visits with interappointment medication of $2 \%$ chlorhexidine and calcium hydroxide for two weeks. The outcome of the retreatment was evaluated 12-24 months after the definitive obturation of the root canal system. 
Intracanal placement of calcium hydroxide has been proposed in necrotic cases because of its antimicrobial properties. It has been reported that treatment with calcium hydroxide results in high frequency of periapical healing and some lesions, especially those of younger patients, are significantly reduced or had completely disappeared in only 1-3 months after the treatment $(32,33)$. Calcium hydroxide is proven to assist periapical healing by its antibacterial properties and also by its biological action facilitating osseous repair (34).

Calcium hydroxide has been considered the gold standard for optimal disinfection of root canals (35). As intracanal medication it is chosen for reasons such as: bacteriostatic properties due to its high $\mathrm{pH}$, being biocompatible, favoring apical repair, and the fact that its presence inside the root canal is accepted for relatively long periods (36).

Induction of hard tissue formation apically is dependent on the presence of the calcium hydroxide material for longer periods (37).

\section{Orthograde Root Canal Treatment}

In the past it was considered that large periapical lesions would not respond to root canal treatment alone and that surgery was always required. In recent years, when there is greater awareness of the root canal morphology as well as development of newer instruments, techniques and materials, the clinician's abilities are strongly enhanced (8).

Elimination of bacteria from the root canal is the most important factor for the successful treatment outcome of periapical lesions. The lack of regression of such lesions is generally due to the persistence of bacteria inside the root canal. The mechanical preparation and irrigation of the root canal system aid in reducing the microbial flora of infected root canals (8). Irrigating solutions such as $\mathrm{NaOCl}$, citric acid, EDTA, chlorhexidine and others help reduce the microbial flora of the infected canals, and the ultrasonic activation of the irrigants increases their efficiency $(38,39)$. It is proven that ultrasonically activated warm sodium hypochlorite can better dissolve and eliminate necrotic tissue $(11,40,41)$. According to some authors if the endodontic infection is eliminated, the immune system is able to promote lesion repair $(21,42)$. Persistent periapical radiolucency after endodontic procedures may decrease, re- main unchanged or increase over time. Clinicians should consider factors including the quality of the current root canal treatment and the patient's symptoms before intervention (43).

In addition the use of intracanal medication after chemomechanical preparation provides better chance of periapical repair, since the mechanical preparation by itself does not reach all the lateral root canals or dental tubules (44).

\section{Lesion Sterilization and Repair Therapy}

This therapy was developed by the Cariology Research Unit of the Niigata University School of Dentistry and uses a triple antibiotic paste of ciprofloxacin, metronidazole and minocycline for disinfection of periradicular lesions as well as dentinal and pulpal lesions. The concept is based on the statement that repair of damaged tissues can be expected if lesions are disinfected (45). Metronidazole is the first choice because it has a wide antibacterial spectrum against anaerobes. But because some of the bacteria are resistant to metronidazole, the other twodrugs are added to the mix (2). The commercially available mixtures are mixed in ratio of 1:3:3 or $1: 1: 1(45,46)$. Although the quantity of the drugs in this therapy is very small, patients should be previously checked for sensitivity to chemicals or antibiotics (47). A disadvantage of the triple antibiotic paste is the following tooth discoloration induced by minocycline. Other medicaments such as cefaclor and fostomycin are proposed as possible alternatives, but further clinical studies are needed to demonstrate their efficacy in the root canal (48).

\section{Apexum Procedure}

This procedure uses two rotary devices, the ApexumNiTi Ablator and Apexum PGA Ablator (Apexum Ltd, Or Yehuda, Israel), designed to extend beyond the apex and mince the periapical tissues on rotation in a low-speed headpiece followed by washing out the minced tissues (49). This procedure is based on the finding that surgically treated periapical lesions show enhanced healing kinetics compared to nonsurgically treated ones (13). Surgical removal of chronically inflamed tissue allows a fresh blood clot to form, thereby converting a chronic inflammatory lesion into a new granulation tissue, where healing might proceed much faster $(50,51)$. A clinical trial reported significantly faster periapical 
healing in the Apexum-treated group (95\%) than in the conventional treated group (39\%) 6 months after the treatment, with significantly less postoperative discomfort or pain. However, whether the procedure was able to remove all the periapically inflamed tissues or not, was not investigated. Further studies regarding this procedure are in progress (13).

\section{Materials UnderResearch and Investigation}

Simvastatin (52) is used as a cholesterol reducing agent that also possesses anti-inflammatory activities. It is proven to have significantly suppressed the progression of induced periapical lesions, possibly by diminishing the cysteine-rich 61 expression in osteoblasts, which in turn suppressed the infiltration of macrophages.

Epigallocatechin - 3 - gallate (53) is a major polyphenol of green tea that has anti-inflammatory properties. It is proven to have suppressed the progression of apical periodontitis in induced periapical lesions.

\section{DISCUSSION}

The management of large periapical lesions is the subject of prolonged debates. The treatment options vary from orthograde root canal treatment or long-term calcium hydroxide therapy to numerous surgical interventions (28). These treatment options can also be combined (54). Instrumentation along with irrigation is the foundation stone of a successful root canal treatment. Both of them reduce bacterial presence. Bhaskar (55) suggested that if instrumentation if performed $1 \mathrm{~mm}$ beyond the apex, the cyst lining gets destroyed and this automatically transforms the lesion into a granuloma. Penetration into the apical zone can also contribute to the healing process by establishing drainage and pressure relief. On the other hand this could also cause epithelial proliferation and even cyst expansion and thereby can lead to a negative outcome (56).

Recently, the role of interleukin (Il-6) in apical periodontitis pathogenesis and whether it could be used as a biomarker for predicting the progression of bone resorption has been discussed. Il- 6 levels were proven higher in symptomatic, epithelialized, and large lesions than in small and asymptomatic ones. Increasing Il-6 leads to bone resorption in the presence of infection (57).
A thorough clinical examination, radiographic investigation, analysis of past and present medical history and pulp vitality test are essential tools for developing a correct diagnosis of periapical lesions, which can lead to choosing the suitable treatment option $(11,58)$.

Numerous authors have stressed on the importance of a long term observation for conservative treated teeth with periapical pathology in order to assess a healing process $(6,53)$. Repair of periradicular tissues consists of regeneration, involving bone, periodontal ligament and cementum. The bone loss area size decreases and the radiographic density increases. If the cortical plate is perforated, healing begins with the regeneration of the external cortical plate and proceeds from the outside of the lesion towards the inside (2). The relative absence of clinical symptoms in chronic apical periodontitis cases makes the healing assessment mostly the radiographic one. Various methods can be used to assess the healing by periodic radiographic recalls (59). Using the periapical index, CBCT-imaging techniques and color ultrasound Doppler are methods that have been used to assess the healing process (1,60-62).

\section{CONCLUSION}

Non-surgical management of periapical lesions have shown a high success rate, therefore it should always be adopted as a routine measure of management. The decompression and aspiration-irrigation techniques can be applied in cases when there is a massive drainage of cystic fluid from the root canals. When this is not the case an intracanal medicament can prove beneficial. Regardless of the chosen treatment method regular periodic reviews and assessment of the healing process of periapical lesions are essential. The surgical approach can be adopted for cases, refractory to non-surgical management when patency along the root canal cannot be assured due to intracanal obstructions or for lesions of non-endodontic origin.

\section{REFERENCES}

1. Karunakaran JV, Abraham CS, Karthik AK, Jayaprakash N. Successful nonsurgical management of periapical lesions of endodontic origin: A Conservative orthograde approach. J Pharm Bioallied Sci. 2017; 9(1): 246-51. 
2. Fernandes M, de Ataide I. Nonsurgical management of periapical lesions. J Conserv Dent. 2010; 13(4): 240-5. doi: 10.4103/0972-0707.73384.

3. Croitoru IC, CrăiŢoiu Ş, Petcu CM, Mihăilescu OA, Pascu RM, Bobic AG, et al. Clinical, imagistic and histopathological study of chronic apical periodontitis. Rom J MorpholEmbryol. 2016; 57(2):719-28.

4. Lin LM, Huang GT, Rosenberg PA. Proliferation of epithelial cell rests, formation of apical cysts, and regression of apical cysts after periapical wound healing. J Endod. 2007; 33(8):908-16. doi: 10.1016/j. joen.2007.02.006.

5. Santos Soares SM, Brito-Júnior M, de Souza FK, Zastrow EV, Cunha CO, Silveira FF, et al. Management of Cyst-like periapical lesions by orthograde decompression and long-term calcium hydroxide/chlorhexidine intracanal dressing: A case series. J Endod. 2016; 42(7):1135-41. doi: 10.1016/j. joen.2016.04.021.

6. Calişkan MK. Prognosis of large cyst-like periapical lesions following nonsurgical root canal treatment: a clinical review. Int Endod J. 2004; 37(6):408-16. doi: 10.1111/j.1365-2591.2004.00809.x.

7. Soares J, Santos S, Silveira F, Nunes E. Nonsurgical treatment of extensive cyst-like periapical lesion of endodontic origin. Int Endod J. 2006; 39(7):566-75. doi: 10.1111/j.1365-2591.2006.01109.x.

8. Saatchi M. Healing of large periapical lesion: a non-surgical endodontic treatment approach. Aust Endod J. 2007;33(3):136-40. doi: 10.1111/j.1747-4477.2007.00061.x.

9. Ghorbanzadeh S, Ashraf H, Hosseinpour S, Ghorbanzadeh F. Nonsurgical management of a large periapical lesion: A case report. Iran Endod J. 2017; 12(2):253-6. doi: 10.22037/iej.2017.49.

10. Borisova-Papancheva T, Panov V, Papanchev G, Peev S. Conservative non-surgical management of an extensive periapical lesion - a case report. Medinform. 2015; 2(4): 364-9.

11. Oztan MD. Endodontic treatment of teeth associated with a large periapical lesion. Int Endod J. 2002; 35(1):73-8.

12. Lin LM, Ricucci D, Lin J, Rosenberg PA. Nonsurgical root canal therapy of large cyst-like inflammatory periapical lesions and inflammatory apical cysts. J Endod. 2009; 35(5):607-15. doi: 10.1016/j. joen.2009.02.012.

13. Metzger Z, Huber R, Slavescu D, Dragomirescu D, Tobis I, Better H. Healing kinetics of periapical le- sions enhanced by the apexum procedure: a clinical trial. J Endod. 2009; 35(2):153-9. doi: 10.1016/j. joen.2008.11.019.

14. Kalender A, Aksoy U, Basmaci F, Orhan K, Orhan AI. Cone-beam computed tomography analysis of the vestibular surgical pathway to the palatine root of the maxillary first molar. Eur J Dent. 2013; $7(1): 35-40$.

15. Kim SG. Variations in outcome of endodontic surgery. In: Tsesis I, editor. Complications in endodontic surgery: Prevention, identification and management. Berlin Heidelberg: Springer; 2014. pp. 39-51.

16. Borisova-Papancheva T, Papanchev G, Peev S, Georgiev T. Posterior endodontic surgery - a case report. Medinform. 2016; 1: 389-93.

17. Scarfe WC, Levin MD, Gane D, Farman AG. Use of cone beam computed tomography in endodontics. Ind J Dent. 2009:634567. doi: 10.1155/2009/634567.

18. Khaki S, Samakhoon SI. Cone beam-computed tomography applications in endodontics: A review. Int J Contemp Dent Med Rev. 2016. doi: 10.15713/ ins.ijcdmr.103.

19. Patel S, Durack C, Abella F, Roig M, Lemberg K. Cone beam computed tomography in endodontics - a review. Int Endod J. 2014;48(1):3-15. doi: 10.1111/ iej.12270.

20. Simon JHS, Enciso R, Malfaz J, Roges R, BaileyPerry M, et al. Differential diagnosis of large periapical lesions using cone-beam computed tomography measurements and biopsy. J Endod. 2006; 32(9): 833-7. doi: 10.1016/j.joen.2006.03.008.

21. Sood N, Maheshwari N, Gothi R, Marwah N. Treatment of large periapical cyst like lesion: a noninvasive approach: a report of two cases. Int J Clin Pediatr Dent. 2015; 8(2):133-7. doi: 10.5005/ jp-journals-10005-1299.

22. Toller PA. Newer concepts of odontogenic cysts. Int J Oral Surg. 1972; 1(1):3-16.

23. Loushine RJ, Weller RN, Bellizzi R, Kulild JC. A 2-day decompression: A case report of a maxillary first molar. J Endod. 1991; 17(2):85-7. doi: 10.1016/ S0099-2399(06)81614-6.

24. Martin SA. Conventional endodontic therapy of upper central incisor combined with cyst decompression: a case report. J Endod. 2007; 33(6):753-7. doi: 10.1016/j.joen.2007.01.013. 
Tsvetelina Borisova-Papancheva, Slavena Svetlozatova

25. Mejia JL, Donado JE, BasraniB. Active nonsurgical decompression of large periapical lesions--3 case reports. J Can Dent Assoc. 2004; 70(10):691-4.

26. Hoen MM, LaBounty GL, Strittmatter EJ. Conservative treatment of persistent periradicular lesions using aspiration and irrigation. J Endod. 1990; 16(4):182-6. doi: 10.1016/S0099-2399(06)81968-0.

27. Fernandes M, De Ataide I. Non-surgical management of a large periapical lesion using a simple aspiration technique: a case report. Int Endod J. 2010 43(6):536-42. doi: 10.1111/j.1365-2591.2010.01719.x.

28. Gupta S, Kulkarni P, Bansal A, Jain A. Non-surgical management of periapical lesion. IOSR-JDMS. 2015;14( 8):105-8. doi:10.6084/m9.figshare.1524125. v1.

29. Al Khasawnah Q, Hassan F, Malhan D, Engelhardt M, Daghma DES, Obidat D, et al. Nonsurgical clinical management of periapical lesions using calcium hydroxide-iodoform-siliconoil paste. Biomed Res Int. 2018; 2018:8198795. doi: $10.1155 / 2018 / 8198795$.

30. Andreasen JO, Munksgaard EC, Bakland LK. Comparison of fracture resistance in root canals of immature sheep teeth after filling with calcium hydroxide or MTA. Dent Traumatol. 2006; 22(3):1546. doi: 10.1111/j.1600-9657.2006.00419.x.

31. Nesković J, Zivković S, Medojević M, Maksimović M. Outcome of orthograde endodontic retreatment-A two-year follow-up. Srp Arh Celok Lek. 2016; 144(3-4):174-80.

32. Ashraf H, Paymanpour P, Bidabadi MM, Hajrezai R. Healing of an extensive periradicular lesion subsequent to a proper endodontic treatment of a mandibular first premolar with complex anatomy. Case Rep Dent. 2013;2013:972093. doi: 10.1155/2013/972093.

33. Binnie WH, Mitchell DF. Induced calcification in the subdermal tissues of the rat. Journal of Dental Research. 1973; 52(5):1087-91. doi: 10.1177/00220345730520051701.

34. Filho MT, Leonardo MR, da Silva LAB. Effect of irrigating solution and calcium hydroxide root canal dressing on the repair of apical and periapical tissues of teeth with periapical lesion. J Endod. 2002; 28(4): 295-9.

35. Portenier I, Haapasalo H, Rye A, Waltimo T, Ørstavik D, Haapasalo M. Inactivation of root canal medicaments by dentine, hydroxylapa- tite and bovine serum albumin. Int Endod J. 2001;34(3):184-8.

36. Barbosa AFA, Lopes CS, Silva LC, Filho IJZ, Nicolí NVV. Large periapical cyst regression by endodontic treatment. OHDM. 2017; 16(6):1-5.

37. Leonardo MR, Hernandez MEFT, Silva LAB, Tanomaru Filho M. Effect of a calcium hydroxide based root canal dressing on periapical repair in dogs: a histological study. Oral Surg Oral Med Oral Pathol Oral Radiol Endod. 2006; 102(5): 680-5.

38. Zehnder M. Root canal irrigants. J Endod. 2006;32(5):389-98. doi.:10.1016/j.joen.2005.09.014.

39. Kandaswamy D, Venkateshbabu N. Root canal irrigants. J Conserv Dent. 2010; 13(4): 256-64. doi: 10.4103/0972-0707.73378.

40. Iandolo A, Amato M, Dagna A, Poggio C, Abdellatif $\mathrm{D}$, Franco V, et al. Intracanal heating of sodium hypochlorite: Scanning electron microscope evaluation of root canal walls. J Conserv Dent. 2018; 21(5):569-73. doi: 10.4103/JCD.JCD_245_18.

41. Mohammadi Z, Shalavi S, Giardino L, Palazzi F, Asgary S. Impact of ultrasonic activation on the effectiveness of sodium hypochlorite: A review. Iran Endod J. 2015; 10(4):216-20. doi: 10.7508/ iej.2015.04.001.

42. Valois CRA, Costa-Júnior ED. Periapical cyst repair after nonsurgical endodontic therapy case report. Braz Dent J. 2005; 16(3):254-8. doi: / S0103-64402005000300016.

43. Huh J, Yang D, Jeon K, Shin S. Progression of periapical cystic lesion after incomplete endodontic treatment. Restor Dent Endod. 2016; 41(2):137-42. doi: 10.5395/rde.2016.41.2.137.

44. Santos Soares SM, Brito-Júnior M, de Souza FK, Zastrow EV, Cunha CO, Silveira FF, et al. Management of cyst-like periapical lesions by orthograde decompression and long-term calcium hydroxide/ chlorhexidine intracanal dressing. J Endod. 2016;42(7):1135-41. doi: 10.1016/j.joen.2016.04.021.

45. Takushige T, Cruz EV, Asgor Moral A, Hoshino E. Endodontic treatment of primary teeth using a combination of antibacterial drugs. Int Endod J. 2004; 37(2):132-8.

46. Er K, Kuştarci A, Ozan U, Taşdemir TJ. Nonsurgical endodontic treatment of dens invaginatus in a mandibular premolar with large periradicular lesion: a case report. J Endod. 2007; 33(3):322-4. doi: 10.1016/j.joen.2006.09.001. 
47. Ozan U, Er K. Endodontic treatment of a large cyst-like periradicular lesion using a combination of antibiotic drugs: a case report. J Endod. 2005; 31(12):898-900.

48. Kim JH, Kim Y, Shin SJ, Park JW, Jung IY. Tooth discoloration of immature permanent incisor associated with triple antibiotic therapy: a case report. J Endod. 2010; 36(6):1086-91. doi: 10.1016/j. joen.2010.03.031.

49. Metzger Z, Huber R, Tobis I, Better H. Enhancement of healing kinetics of periapical lesions in dogs by the Apexum procedure. J Endod. 2009; 35(1):40-5. doi: 10.1016/j.joen.2008.10.002.

50. Metzger Z, Abramovitz I. Periapical lesions of endodontic origin. In: Ingle JI, Bakland LK, Baumgartner JC, editors. Ingle's endodontics. 6th ed. Hamilton, ON, Canada: B C Decker; 2008. pp. 494-519.

51. Metzger Z. Macrophages in periapical lesions. Endod Dent Traumatol. 2000; 16(1):1-8.

52. Lin SK, Kok SH, Lee YL, Hou KL, Lin YT, Chen $\mathrm{MH}$, et al. Simvastatin as a novel strategy to alleviate periapical lesions. J Endod. 2009; 35(5):657-62. doi: 10.1016/j.joen.2009.02.004.

53. Lee YL, Hong CY, Kok SH, Hou KL, Lin YT, Chen $\mathrm{MH}$, et al. An extract of green tea, epigallocatechin3-gallate, reduces periapical lesions by inhibiting cysteine-rich 61 expression in osteoblasts. J Endod. 2009; 35(2):206-11. doi: 10.1016/j.joen.2008.11.015.

54. Campo N. Large periapical lesion management: Decompression combined with root-canal treatment. Roots. 2012; 1:6-9.

55. Bhaskar SN. Periapical lesions-types, incidence, and clinical features. Oral Surg Oral Med Oral Pathol. 1966; 21(5):657-71.
56. Seltzer S. Endodontology-biologic considerations in endodontic procedures. 2nd ed. Philadelphia, PA: Lea and Febiger; 1998.

57. Azuma MM, Samuel RO, Gomes-Filho JE, DezanJunior E, Cintra LT. The role of IL- 6 on apical periodontitis: a systematic review. Int Endod J. 2014; 47(7):615-21. doi: 10.1111/iej.12196.

58. Huang HY, Chen YK, Ko EC, Chuang FH, Chen $\mathrm{PH}$, Chen CY, et al. Retrospective analysis of nonendodontic periapical lesions misdiagnosed as endodontic apical periodontitis lesions in a population of Taiwanese patients. Clin Oral Investig 2017;21(6):2077-82. doi: 10.1007/s00784-016-1997-7.

59. Huumonen S, Ørstavik D. Radiological aspects of apical periodontitis. Endod Topics. 2002;1(1):3-25. doi:10.1034/j.1601-1546.2002.10102.x.

60. Rajendran N, Sundaresan B. Efficacy of ultrasound and color power Doppler as a monitoring tool in the healing of endodontic periapical lesions. J Endod. 2007; 33(2):181-6. doi: 10.1016/j. joen.2006.07.020.

61. Schloss T, Sonntag D, Kohli MR, Setzer FC. A comparison of 2- and 3-dimensional healing assessment after endodontic surgery using conebeam computed tomographic volumes or periapical radiographs. J Endod. 2017;43(7):1072-9. doi: 10.1016/j.joen.2017.02.007.

62. Sălceanu M, Vataman M, Aminov L, Giuroiu C, Topoliceanu C, et al. Diagnosis and follow-up of the periapical lesions in the non-surgical endodontic treatment: a CBCT study. Romanian J Oral Rehabil. 2017; 9(2):32-6. 